\title{
Characteristics of Patients With Rheumatoid Arthritis in Turkey: Results From the Turkish League Against Rheumatism Rheumatoid Arthritis Registry
}

Ajda BAL, ${ }^{1}$ Şebnem ATAMAN, ${ }^{2}$ Hatice BODUR, ${ }^{3}$ Aylin REZVANI, ${ }^{4}$ Nurdan PAKER, ${ }^{5}$ Nurettin TAŞTEKİN, ${ }^{6}$ Altınay GÖKSEL KARATEPE, ${ }^{7}$ Pınar BORMAN, ${ }^{8}$ Mahmut YENER, ${ }^{9}$ Kemal NAS, ${ }^{10}$ Melek SEZGIN,${ }^{11}$ Pelin YAZGAN, ${ }^{12}$ İbrahim TEKEOĞLU, ${ }^{10}$ Beril DOĞU, ${ }^{13}$ Zuhal ALTAY, ${ }^{14}$ Mehmet KIRNAP, ${ }^{15}$ Alev GÜRGAN,${ }^{16}$ Ali GÜR, ${ }^{17}$ Sami HİZMETLİ, ${ }^{18}$ Zafer GÜNENDİ, ${ }^{19}$ Rana ERDEM, ${ }^{20}$ Hatice UĞURLU, ${ }^{21}$ Elem İNAL, ${ }^{22}$ Neşe ÖLMEZ, ${ }^{16}$ Erkan KOZANOĞLU, ${ }^{23}$ Öznur ÖKEN, ${ }^{24}$ Sumru ÖZEL, ${ }^{24}$ Ümit DÜNDAR,,${ }^{25}$ Ayşen AKINCI, ${ }^{8}$ Cihat ÖZTÜRK, ${ }^{26}$ Konçuy SIVRİĞLU, ${ }^{27}$ Mehmet Tuncay DURUÖZ, ${ }^{28}$ Ece AYDOĞ,,${ }^{29}$ Erhan ÇAPKIN, ${ }^{30}$ Lale ALTAN, ${ }^{27}$ Deniz EVCIK, ${ }^{31}$ Oğuz DURMUS, ${ }^{32}$ İlker YAĞCI, ${ }^{28}$ Ömer Faruk ŞENDUR, ${ }^{33}$ Filiz Meryem SERTPOYRAZ, ${ }^{34}$ Ahmet ÖZGÜL, ${ }^{35} \mathrm{Kazım}$ ŞENEL, ${ }^{36} \mathrm{Kazım} \mathrm{ÇAPACI}^{26}$

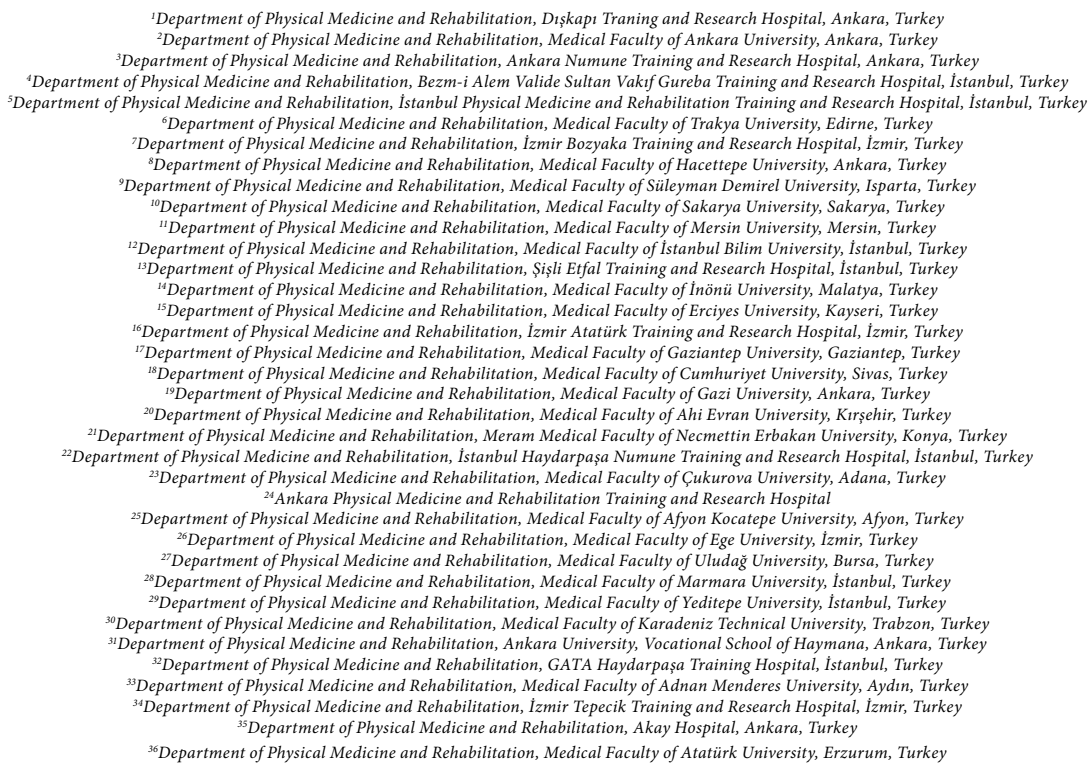

\section{ABSTRACT}

Objectives: This study investigates the demographic and clinical characteristics of patients with rheumatoid arthritis (RA) in Turkey, and attempts to identify strategies for the prevention, treatment, and support of RA.

Patients and methods: A total of 2,359 patients (1,966 females, 393 males; mean age $51.6 \pm 12.5$ years; range 18 to 75 years) with RA from 36 centers across Turkey, who were recorded in the Turkish League Against Rheumatism (TLAR) RA Registry between September 2007 and March 2011, were evaluated. Patients' demographic and clinical data were recorded. Disease activity, functional status, and radiographic damage were measured using the Disease Activity Score 28, the Health Assessment Questionnaire, and van der Heijde modified Sharp scoring method.

Results: The mean duration of academic education received was $5.2 \pm 3.8$ years, and $74.6 \%$ of the patients were homemakers. Non-biological diseasemodifying anti-rheumatic drugs were used by $91.0 \%$ of the patients, while $10.2 \%$ used biological disease-modifying anti-rheumatic drugs. The mean Disease Activity Score 28, Health Assessment Questionnaire, and Sharp scores were $4.0 \pm 1.4,0.38 \pm 0.37$, and $31.2 \pm 57.1$, respectively. Of the patients, $17.8 \%$ were in remission and $14.1 \%$ had low disease activity rates, while $42.7 \%$ and $25.5 \%$ had moderate and high disease activity rates.

Conclusion: The majority of patients with RA in Turkey are middle-aged homemakers. Despite the high rates of disease-modifying anti-rheumatic drugs use, the majority of patients had moderate and high disease activity. These findings indicate that treatment needs of RA patients are not met sufficiently. Keywords: Patient characteristics; registry; rheumatoid arthritis.

Received: October 23, 2013 Accepted: January 11, 2014 Published online: December 09, 2014

Correspondence: Ajda Bal, M.D. Dışkapı Eğitim ve Araştırma Hastanesi Fizik Tedavi ve Rehabilitasyon Kliniği, 06330 Dışkapı, Ankara, Turkey.

Tel: +90 312 - 5962993 e-mail: ajdabal@yahoo.com

@2015 Turkish League Against Rheumatism. All rights reserved. 
Rheumatoid arthritis (RA) is a chronic inflammatory disease with a prevalence of $1 \%$, which mainly affects the synovial joints. RA can lead to significant functional loss and disability due to joint damage. It is also a great burden on the individual, society, and the health care system. To reduce the negative effects of the disease on the quality of life and socio-economic burden, one should have a better understanding of RA in every aspect. Therefore, epidemiological data, clinical information concerning risk factors, comorbidities, complications and sequelae, and cost analyses are needed. These data are required to adopt the most appropriate management approach for RA patients. ${ }^{1-3}$

Information regarding RA can easily be reached in findings of clinical trials which investigate patients with RA. However, the patients who take part in clinical trials are usually selected according to strict criteria, and therefore are not a true reflection of real-life patients. In recent years, RA registries have been created in many countries to gather information about patients outside of clinical trials, and to be able to follow these patients. The registration of RA patients has provided a better understanding of patients' demographic and clinical characteristics, and the long-term effectiveness and side effects of new drugs. ${ }^{4-8}$ In Turkey, the first registry for RA, was initiated in 2007 by Turkish League Against Rheumatism (TLAR).

The aim of this study was to determine the demographic and clinical characteristics of patients with RA in Turkey, and thus to shed light on disease prevention, treatment and support strategies required by this patient group.

\section{PATIENTS AND METHODS}

In this study, a total of 2,359 patients $(1,966$ females, 393 males; mean age 51.6 $6 \pm 12.5$ years; range 18 to 75 years) in the TLAR RA registry were evaluated. The registry consists of web-based patient data from 36 centers in different regions of Turkey between September 2007 and March 2011. Patients who were over the age of 18 and met the diagnostic criteria of RA according to the 1987 American College of Rheumatology were included. ${ }^{9}$
Before the study began, an interactive meeting consisting of the practical applications was held to ensure that the researchers would carry out the assessments in a standardized fashion. In addition, a booklet for physical and radiographic evaluation methods was prepared for the participating centers. The study was approved by the ethics committees, and informed consents were obtained from all patients.

The evaluations were carried out by physicians in the centers where the patients were being treated and followed-up. The demographic characteristics including age, sex, level of education, employment status, marital status, age at onset, disease duration, smoking and alcohol consumption, tuberculosis history, family history of RA, and exercise habits were recorded. The clinical features including body mass index (BMI), comorbid diseases, extra-articular involvement, history of joint surgery, and drugs used [disease-modifying antirheumatic drugs (DMARDs), biological agents, corticosteroids] were determined. Physical examination consisted of the evaluation of rheumatoid nodules, and all 28 joints for tenderness and swelling. Erythrocyte sedimentation rate $(\mathrm{ESR}, \mathrm{mm} / \mathrm{h})$ and rheumatoid factor (a value $\geq 15 \mathrm{IU} / \mathrm{ml}$ was accepted positive) tests were performed.

The disease activity was measured using the disease activity score 28 (DAS28), which consists of the examination of tender and swollen joints (from 28 joints), patient global assessment (PGA), measured with a 0-100 $\mathrm{mm}$ visual analog scale, and ESR. DAS28 is calculated using the following formula: DAS28 $=0.56$ *sqrt (number of tender joints) +0.28 *sqrt (number of swollen joints $)+0.70 * \operatorname{Ln}(\mathrm{ESR})+0.014^{*} \mathrm{PGA} .{ }^{10} \mathrm{DAS} 28$ values $\leq 2.6$ were considered as indicating disease remission, $>2.6$ to $\leq 3.2$ as low disease activity, $>3.2$ to $\leq 5.1$ as moderate disease activity, and $>5.1$ as high disease activity. ${ }^{11}$ The patient's functional status was determined by the selfreport Health Assessment Questionnaire (HAQ), for which Turkish validity and reliability studies have been performed. HAQ consists of eight subsections of 20 questions and subsections involving dressing, eating, standing, walking, hygiene, reaching, grasping, and daily activities. Zero to three points were assigned in response to each question $(0=$ ability to perform activity easily, $1=$ little disability in performing activity, 
$2=$ difficulty in performing activity, $3=$ not able to perform activity). The total score was determined by calculating the mean of the highest points in the subdivisions. If the patient required assistance by another individual or used a device to perform the activity, a score of zero or one given for that question was increased to two. ${ }^{12,13}$ Radiological findings were identified according to the van der Heijde modification of the Sharp method using anterior-posterior hand and foot radiographs. Using this method, the erosion score is calculated by studying 16 regions on the hand, and six regions on the foot, and scored between 0-5. Joint narrowing is assessed by studying 16 regions on the hand and six regions on the foot, and scored between $0-4$. The total score is $448 .{ }^{14}$

\section{Statistical analysis}

Statistical Package for the Social Sciences version 15.0 for Windows (SPSS Inc., Chicago, IL, USA) was used for statistical analysis. A total of 2,359 patients were included in the analysis. Frequency tables were presented for the categorical variables, and descriptive statistics (mean, standard deviation, and median) for the numeric variables.

Table 1. Demographic characteristics of rheumatoid arthritis patients

\begin{tabular}{lccc}
\hline Characteristic & $\mathrm{n}$ & $\%$ & Mean $\pm \mathrm{SD}$ \\
\hline Age (year) & & & $51.6 \pm 12.5$ \\
Sex & 1966 & 83.3 & \\
$\quad$ Female & 393 & 16.7 & $5.2 \pm 3.8$ \\
$\quad$ Male & & & \\
Education level (year) & & & \\
Occupational status & 289 & 12.3 & \\
$\quad$ Employed & 41 & 1.7 & \\
$\quad$ Unemployed & 1759 & 74.6 & \\
$\quad$ Homemaker & 252 & 10.7 & \\
$\quad$ Retired & 17 & 0.7 & \\
$\quad$ Student & 348 & 14.8 & \\
Marital status & 2011 & 85.2 & $11.9 \pm 8.7$ \\
$\quad$ Single & & & $41.2 \pm 13.6$ \\
$\quad$ Married & & & \\
Disease duration (year) & 66 & 2.8 & \\
Age at disease onset (year) & & \\
$\quad<16$ & 2283 & 97.2 & \\
$\quad \geq 16$ & 155 & 7.1 & \\
Exercises habit & 356 & 16.2 & \\
Smoking habit & 44 & 2.0 & \\
Alcohol consumption & 479 & 20.3 & \\
Family history of RA & 54 & 2.5 & \\
History of tuberculosis & 54 & \\
\hline SD: Standard deviation; RA: Rheumatoid arthritis. & & \\
\end{tabular}

\section{RESULTS}

The demographic characteristics of the patients are shown in Table 1, and the clinical features are shown in Table 2. Disease activity, functional status, and radiographic scores are presented in Table 3.

The mean years of received academic education were $5.2 \pm 3.8$, and $74.6 \%$ of the patients were homemakers. The mean disease duration was $11.9 \pm 8.7$ years. Seven point one percent took regular exercise, $16.2 \%$ were smokers and $2 \%$ consumed alcohol. The most common extraarticular signs were those involving the eyes (4.8\%) and the lungs (3.9\%). Comorbid diseases were observed in $57.1 \%$ of the patients. Non-biological DMARDs were used by $91.0 \%$ of the patients, while $10.2 \%$ used biological DMARDs. The mean DAS28, HAQ, and Sharp scores were $4.0 \pm 1.4,0.38 \pm 0.37$ and $31.2 \pm 57.1$, respectively. Seventeen point eight percent of the patients

Table 2. Clinical characteristics of rheumatoid arthritis patients

\begin{tabular}{|c|c|c|c|}
\hline Characteristic & $\mathrm{n}$ & $\%$ & Mean \pm SD \\
\hline Body mass index $\left(\mathrm{kg} / \mathrm{m}^{2}\right)$ & & & $28 \pm 5.3$ \\
\hline \multicolumn{4}{|l|}{ Extra-articular involvement } \\
\hline Pulmonary & 85 & 3.9 & \\
\hline Ocular & 106 & 4.8 & \\
\hline Renal & 13 & 0.6 & \\
\hline Neurologic & 6 & 0.3 & \\
\hline Sjögren's syndrome & 34 & 1.6 & \\
\hline Cardiac & 17 & 0.8 & \\
\hline Vasculitis & 7 & 0.3 & \\
\hline Lymphedema & 3 & 0.1 & \\
\hline \multicolumn{4}{|l|}{ Comorbidities } \\
\hline Diabetes mellitus & 175 & 8.0 & \\
\hline Heart disease & 131 & 6.0 & \\
\hline Hypertension & 591 & 26.6 & \\
\hline Thyroid disease & 164 & 7.5 & \\
\hline Peptic ulcer & 296 & 13.4 & \\
\hline Rheumatoid factor positivity & 1633 & 69.2 & \\
\hline Subcutaneous nodule & 69 & 3.2 & \\
\hline Joint surgery & 377 & 31.6 & \\
\hline \multicolumn{4}{|l|}{ Drug use } \\
\hline Non-biological DMARDs & 2061 & 91.0 & \\
\hline Methotrexate & 1451 & 64.1 & \\
\hline Sulfasalazine & 755 & 33.3 & \\
\hline Leflunomide & 464 & 20.5 & \\
\hline $\begin{array}{l}\text { Chloroquine/ } \\
\text { hydroxichloroquine }\end{array}$ & & & \\
\hline hydroxichloroquine & 357 & 15.8 & \\
\hline Biological DMARDs & 230 & 10.2 & \\
\hline Anti-TNF- $\alpha$ & 223 & 9.8 & \\
\hline Others & 7 & 0.4 & \\
\hline Corticosteroid & 987 & 51.4 & \\
\hline
\end{tabular}




\begin{tabular}{|c|c|c|c|c|c|}
\hline Characteristic & $\mathrm{n}$ & $\%$ & Mean \pm SD & Median & Minimum-Maximum \\
\hline Disease activity score 28 & & & $4.0 \pm 1.4$ & 3.96 & $0.0-8.5$ \\
\hline \multicolumn{6}{|l|}{ EULAR disease activity } \\
\hline Remission & 415 & 17.8 & & & \\
\hline Low & 329 & 14.1 & & & \\
\hline Moderate & 996 & 42.7 & & & \\
\hline High & 595 & 25.5 & & & \\
\hline Health assessment questionnaire & & & $0.38 \pm 0.37$ & 0.2 & $0.0-1.5$ \\
\hline Total Sharp score $(n=682)$ & & & $31.2 \pm 57.1$ & 6.0 & $0.0-445.0$ \\
\hline
\end{tabular}

were in remission, $14.1 \%$ had low disease activity rates, while $42.7 \%$ and $25.5 \%$ had moderate and high disease activity rates, respectively.

\section{DISCUSSION}

The data of 2,359 patients were obtained from TRASD-IP, within the scope of TLAR, which is the first RA registry in Turkey. Clinical and demographic characteristics were evaluated using this data.

Rheumatoid arthritis registries evaluate patients' health status, disease course, mortality, drug side effects, costs, and labor productivity. Arthritis registries were first created in the 1980s. The RA registries may vary according to the characteristics of the patients, and may be based on rheumatic diseases, ${ }^{15-17}$ early arthritis, ${ }^{8}$ early RA, ${ }^{17-19}$ established $\mathrm{RA},{ }^{7,20}$ and biological agent, ${ }^{5,21,22}$ or DMARD ${ }^{23}$ registries. In the TLAR registry, all patients older than 18 years of age with any kind of therapy or disease stage were recorded and monitored, and their real-life data was collected.

The mean age in the RA registries from other countries is between 50-68 years. That of the TLAR registry was also similar, although slightly younger (51.6 years). ${ }^{15,24}$ In a study by Sokka et al. ${ }^{25}$ which contains data from 15 countries, the mean age of the RA patients in Turkey was younger than in other countries. This is an expected result due to Turkey's largely young population.

Rheumatoid arthritis is three times more frequent in women than in men. Hormonal factors are thought to be responsible for this phenomenon. ${ }^{26}$ This rate was similar in the TLAR and other RA registries. ${ }^{24,25}$
The mean disease duration was 11.9 years, which is similar to the findings of other studies. ${ }^{24,25}$ RA has been considered to begin at 40-50 years of age. In this study, the age of onset was 41.2 years, which is lower than that of other RA registries. ${ }^{5,15}$

Some studies have shown that the level of education may affect the prognosis of RA. ${ }^{27}$ It is thought that low levels of education may be associated with poor compliance to treatment. Therefore, the high disease activity of patients in the TLAR registry may be associated with a low level of education.

The vast majority of patients in the RA registry in Turkey are women. Therefore, RA can lead to dysfunction in the roles of housewives, which in turn will cause loss of labor at home, resulting in an increase in the indirect costs of the disease. ${ }^{28}$

Exercise enhances the maintenance of range of motion, and improves the muscle strength and coordination. Furthermore, exercise has been shown to reduce pain and ESR in patients with RA. ${ }^{29}$ The low rate of regular exercise taken by the population in our study suggests that patients need to be better educated on the importance of taking regular exercise.

Smoking is recognized as a risk factor for RA development and poor outcomes. ${ }^{30,31}$ In this study, the rate of smoking was lower compared to some RA registries, while it was higher than some of them. ${ }^{24}$ All the patients with RA should be informed about the negative effects of smoking on RA. The use of alcohol, which may increase DMARDs-induced liver toxicity, was not common among the patients.

First degree relatives of patients with RA have been reported to have an increased risk of 
developing RA. ${ }^{32}$ Approximately one fifth of the patients had a family history of RA.

Latent tuberculosis, which continues to be a major problem in Turkey, should be screened prior to administering biological treatments. Therefore, the guide for national tuberculosis screening is applied to the patients before starting any biological treatment. Even so, $2.5 \%$ of the patients had a history of tuberculosis. In Turkey, this issue should be kept in mind before commencing treatment with biological agents.

The mean BMI was high. Since a high BMI is associated with poor outcomes in patients with RA and causes negative effects on the treatment, care should be taken to maintain weight control. . $^{33,34}$

Extra-articular involvement also plays an important role in the follow-up and treatment of patients with RA. The most common comorbid diseases in the current study were hypertension and peptic ulcers. In the Giese registry, the most common comorbid disease was hypertension as well. ${ }^{5}$ In patients with RA, the increased risk of coronary heart disease due to inflammation may be affected adversely by the presence of hypertension. Therefore, the regulation of blood pressure is extremely important. The increased rate of peptic ulcer disease may be related to the drug treatment for RA, and particularly the use of NSAIDs and corticosteroids.

Rheumatoid factor positivity was detected in $69.2 \%$ of the patients, which is consistent with the literature. ${ }^{13,21}$ In the Norwegian DMARD registry, $19.7 \%$ was positive for rheumatoid nodules, whereas in our RA registry, the rheumatoid nodule rate was extremely low at $3.2 \% .{ }^{23}$ Joint surgery was performed in $31 \%$ of the patients. Surgery also increases the cost of the disease. When compared to past data, the rate of joint surgery seems to have increased. ${ }^{35}$ This is likely due to the increased access to surgical treatment.

In recent years, the proposed approach for RA is to start DMARD therapy in the early stages of onset, before permanent joint damage occurs. ${ }^{36}$ Ninety-one percent of the patients were using a non-biological DMARD, whereas 10\% were treated with biological DMARDs. When compared with the other registries, the nonbiological DMARD use was higher, whereas the use of biological DMARD was lower. ${ }^{15,23,37}$ Half of the patients were on corticosteroid therapy. This is lower when compared to some of the RA registries, and higher than others. ${ }^{24}$ In a previous study from Turkey, use of biological agents was $6.9 \% .{ }^{35}$ The recent data indicate that use of biological drugs has increased in Turkey, as well as all over the world. These data reflect the status 3 years previously and show that the disease activity was high and the use of biological agents was low. Presently, we believe that biological agents are used more frequently. Although it is not consistent with the current treatment strategy, patients showing moderate activity and unresponsiveness to DMARDs are not included in the repayment cover in our country.

Methotrexate remains the gold standard DMARD in the treatment of $\mathrm{RA}$, and it has also been reported to be the most commonly used DMARD in the treatment of RA in various studies. ${ }^{5,23,38}$ In this registry, methotrexate was the most commonly used DMARD, with a higher utilization rate compared to other studies (64.1\%). Corticosteroid and methotrexate utilization rates were similar to the past data from Turkey. ${ }^{35}$ The most commonly used DMARDs second to methotrexate were sulfasalazine, leflunomide, chloroquine and hydroxychloroquine, respectively. Azathioprine, auronophine, cyclosporine, gold thiomalate and d-penicillamine, which were all used in the 1980s and 1990s, are no longer in use in RA patient recorded the registry.

According to EULAR disease activity criteria, more than half of the patients had a moderate or high level of disease activity. This may suggest that, in Turkey, medical treatment is insufficient despite the frequent use of DMARDs, and that the course of the disease is more severe and resistant to treatment. In the study of Sokka et al., ${ }^{25}$ in which data from many countries were evaluated, the mean DAS28 was 4.0. In the same study, the mean DAS28 for Turkey was 4.1. These values are similar to the results of the present study.

Although the disease activity was high in the majority of the patients, it was surprising that the disability levels and the radiographic pathology results were not at an advanced level. RA can lead to functional disability by causing joint deformity and destruction. The disability levels associated with the disease as 
measured by the HAQ were low (0.38). This rate of disability is low compared to the majority of the clinical trials on RA, and past data from Turkey. ${ }^{24,25,35,39}$ The fact that the radiographic findings and levels of disability were low as expected.

This study is important because it contains the results of the first RA register created in Turkey, and includes accessible national data on patients with RA in Turkey. These data may shed light on the prevention, treatment, and support strategies required by these patients. The analysis of the follow-up results of the registry may provide data on the long-term course of the disease, drug side effects, and cost-effectiveness.

The majority of patients with RA in Turkey are middle-aged and homemakers. Higher levels of education may be necessary for compliance to and success of treatment. Despite the high use of DMARDs, the majority of the patients had moderate or high disease activity. These findings indicate that treatment needs for RA patients are not met sufficiently. Thus, we may conclude that the $\mathrm{RA}$ register may aid significantly in obtaining true clinical information.

\section{Acknowledgment}

The authors express their gratitude to all members of TLAR RA Study Group for their cooperation and to Wyeth/Pfizer Company for the sponsorship.

\section{Declaration of conflicting interests}

The authors declared no conflicts of interest with respect to the authorship and/or publication of this article.

\section{Funding}

The authors received no financial support for the research and/or authorship of this article.

\section{REFERENCES}

1. Boonen A, Severens JL. The burden of illness of rheumatoid arthritis. Clin Rheumatol 2011;30 Suppl 1:S3-8.

2. Filipovic I, Walker D, Forster F, Curry AS. Quantifying the economic burden of productivity loss in rheumatoid arthritis. Rheumatology (Oxford) 2011;50:1083-90.

3. Zhang $\mathrm{W}$, Anis AH. The economic burden of rheumatoid arthritis: beyond health care costs. Clin
Rheumatol 2011;30 Suppl 1:S25-32.

4. Kvien TK, Uhlig T. The Oslo experience with arthritis registries. Clin Exp Rheumatol 2003;21:S118-22.

5. Lapadula G, Ferraccioli G, Ferri C, Punzi L, Trotta F; GISEA. GISEA: an Italian biological agents registry in rheumatology. Reumatismo 2011;63:155-64.

6. Sokka T. Rheumatoid arthritis databases in Finland. Clin Exp Rheumatol 2005;23:S201-4.

7. Grazuleviciute E, Dadoniene J. Vilnius rheumatoid arthritis registry. Medicina (Kaunas) 2003;39:505-10. [Abstract]

8. Symmons DP, Silman AJ. The Norfolk Arthritis Register (NOAR). Clin Exp Rheumatol 2003;21:S94-9.

9. Arnett FC, Edworthy SM, Bloch DA, McShane DJ, Fries JF, Cooper NS, et al. The American Rheumatism Association 1987 revised criteria for the classification of rheumatoid arthritis. Arthritis Rheum 1988;31:315-24.

10. Prevoo ML, van 't Hof MA, Kuper HH, van Leeuwen MA, van de Putte LB, van Riel PL. Modified disease activity scores that include twenty-eight-joint counts. Development and validation in a prospective longitudinal study of patients with rheumatoid arthritis. Arthritis Rheum 1995;38:44-8.

11. van Gestel AM, Prevoo ML, van 't Hof MA, van Rijswijk $\mathrm{MH}$, van de Putte LB, van Riel PL. Development and validation of the European League Against Rheumatism response criteria for rheumatoid arthritis. Comparison with the preliminary American College of Rheumatology and the World Health Organization/ International League Against Rheumatism Criteria. Arthritis Rheum 1996;39:34-40.

12. Fries JF, Spitz P, Kraines RG, Holman HR. Measurement of patient outcome in arthritis. Arthritis Rheum 1980;23:137-45.

13. Küçükdeveci AA, Sahin $H$, Ataman S, Griffiths $\mathrm{B}$, Tennant A. Issues in cross-cultural validity: example from the adaptation, reliability, and validity testing of a Turkish version of the Stanford Health Assessment Questionnaire. Arthritis Rheum 2004;51:14-9.

14. van der Heijde D. How to read radiographs according to the Sharp/van der Heijde method. J Rheumatol 1999;26:743-5.

15. Canhão H, Faustino A, Martins F, Fonseca JE; Rheumatic Diseases Portuguese Register Board Coordination, Portuguese Society of Rheumatology. Reuma.pt - the rheumatic diseases portuguese register. Acta Reumatol Port 2011;36:45-56.

16. Kremer JM. The CORRONA database. Autoimmun Rev 2006;5:46-54.

17. Kvien TK, Glennås A, Knudsrød OG, Smedstad LM, Mowinckel P, Førre O. The prevalence and severity of rheumatoid arthritis in Oslo. Results from a county register and a population survey. Scand J Rheumatol 1997;26:412-8.

18. Bridges SL Jr, Hughes LB, Mikuls TR, Howard G, Tiwari HK, Alarcón GS, et al. Early rheumatoid 
arthritis in African-Americans: the CLEAR Registry. Clin Exp Rheumatol 2003;21:S138-45.

19. Sokka T. Early rheumatoid arthritis in Finland. Clin Exp Rheumatol 2003;21:S133-7.

20. van Vollenhoven RF, Askling J. Rheumatoid arthritis registries in Sweden. Clin Exp Rheumatol 2005;23:S195-200.

21. Watson K, Symmons D, Griffiths I, Silman A. The British Society for Rheumatology biologics register. Ann Rheum Dis 2005;64 Suppl 4:iv42-3.

22. Hetland ML. DANBIO: a nationwide registry of biological therapies in Denmark. Clin Exp Rheumatol 2005;23:S205-7.

23. Kvien TK, Heiberg, Lie E, Kaufmann C, Mikkelsen $\mathrm{K}$, Nordvåg BY, et al. A Norwegian DMARD register: prescriptions of DMARDs and biological agents to patients with inflammatory rheumatic diseases. Clin Exp Rheumatol 2005;23:S188-94.

24. Curtis JR, Jain A, Askling J, Bridges SL Jr, Carmona L, Dixon W, et al. A comparison of patient characteristics and outcomes in selected European and U.S. rheumatoid arthritis registries. Semin Arthritis Rheum 2010;40:2-14.

25. Sokka T, Kautiainen H, Toloza S, Mäkinen $\mathrm{H}$, Verstappen SM, Lund Hetland $\mathrm{M}$, et al. QUEST-RA: quantitative clinical assessment of patients with rheumatoid arthritis seen in standard rheumatology care in 15 countries. Ann Rheum Dis 2007;66:1491-6.

26. Fairweather D, Frisancho-Kiss S, Rose NR. Sex differences in autoimmune disease from a pathological perspective. Am J Pathol 2008;173:600-9.

27. Callahan LF, Pincus T. Formal education level as a significant marker of clinical status in rheumatoid arthritis. Arthritis Rheum 1988;31:1346-57.

28. Reisine ST, Goodenow C, Grady KE. The impact of rheumatoid arthritis on the homemaker. Soc Sci Med 1987;25:89-95.

29. Knittle KP, De Gucht V, Hurkmans EJ, Vlieland TP, Peeters AJ, Ronday HK, et al. Effect of selfefficacy and physical activity goal achievement on arthritis pain and quality of life in patients with rheumatoid arthritis. Arthritis Care Res (Hoboken)
2011;63:1613-9.

30. Heliövaara M, Aho K, Aromaa A, Knekt P, Reunanen A. Smoking and risk of rheumatoid arthritis. J Rheumatol 1993;20:1830-5.

31. Papadopoulos NG, Alamanos Y, Voulgari PV, Epagelis EK, Tsifetaki N, Drosos AA. Does cigarette smoking influence disease expression, activity and severity in early rheumatoid arthritis patients? Clin Exp Rheumatol 2005 ;23:861-6.

32. del Junco D, Luthra HS, Annegers JF, Worthington JW, Kurland LT. The familial aggregation of rheumatoid arthritis and its relationship to the HLADR4 association. Am J Epidemiol 1984;119:813-29.

33. Gremese E, Carletto A, Padovan M, Atzeni F, Raffeiner B, Giardina AR, et al. Obesity and reduction of the response rate to anti-tumor necrosis factor $\alpha$ in rheumatoid arthritis: an approach to a personalized medicine. Arthritis Care Res (Hoboken) 2013;65:94-100.

34. Ajeganova S, Andersson ML, Hafström I; BARFOT Study Group. Association of obesity with worse disease severity in rheumatoid arthritis as well as with comorbidities: a long-term followup from disease onset. Arthritis Care Res (Hoboken) 2013;65:78-87.

35. Bodur H, Ataman S, Akbulut L, Evcik D, Kavuncu V, Kaya T, et al. Characteristics and medical management of patients with rheumatoid arthritis and ankylosing spondylitis. Clin Rheumatol 2008;27:1119-25.

36. Mok CC, Tam LS, Chan TH, Lee GK, Li EK; Hong Kong Society of Rheumatology. Management of rheumatoid arthritis: consensus recommendations from the Hong Kong Society of Rheumatology. Clin Rheumatol 2011;30:303-12.

37. Neovius M, Simard JF, Askling J; ARTIS study group. Nationwide prevalence of rheumatoid arthritis and penetration of disease-modifying drugs in Sweden. Ann Rheum Dis 2011;70:624-9.

38. Sokka T. Increases in use of methotrexate since the 1980s. Clin Exp Rheumatol 2010;28:S13-20.

39. Kobelt G, Woronoff AS, Richard B, Peeters P, Sany J. Disease status, costs and quality of life of patients with rheumatoid arthritis in France: the ECO-PR Study. Joint Bone Spine 2008;75:408-15. 